\title{
Robot-Assisted Laparoscopic Vesiculectomy for Large Seminal Vesicle Cystadenoma: A Case Report and Review of the Literature
}

\author{
Riccardo Campi, ${ }^{1}$ Sergio Serni, ${ }^{1}$ Maria Rosaria Raspollini, ${ }^{2}$ Agostino Tuccio, ${ }^{1}$ \\ Giampaolo Siena, ${ }^{1}$ Marco Carini, ${ }^{1}$ Andrea Minervini ${ }^{1}$
}

\section{Clinical Practice Points}

- Primary tumors of seminal vesicles (SVs) are very rare. Differential diagnosis often relies on a multimodality approach comprising magnetic resonance imaging and preoperative biopsies.

- We report a case of a large SV cystadenoma causing gross hematuria and lower urinary tract symptoms managed with nerve-sparing, robot-assisted laparoscopic seminal vesiculectomy.
- Most cases of SV cystadenoma reported in published studies were managed with open, invasive surgical approaches. To date, laparoscopic and robotic seminal vesiculectomy can be safely considered the reference standard treatment of benign tumors of SVs, because they combine a minimally invasive approach with optimal surgical, oncologic, and functional outcomes.

Clinical Genitourinary Cancer, Vol. 13, No. 5, e369-73 (c) 2015 Elsevier Inc. All rights reserved. Keywords: Cystadenoma, Review, Robotic, Seminal vesicles, Vesiculectomy

\section{Case Report Clinical Case}

A 47-year-old patient had been referred to our center for gross hematuria and lower urinary tract symptoms (LUTS). His medical history was unremarkable, and no comorbidities were present. The prostate-specific antigen (PSA) level was $1.7 \mathrm{ng} / \mathrm{mL}$. The digital rectal examination revealed a tense and elastic mass with undefined boundaries, cranially to the prostate. The physical examination and laboratory test results were otherwise normal. Transabdominal ultrasonography showed no lesions in the upper urinary tract; however, high-resolution transrectal ultrasonography (TRUS) confirmed the presence of a multiseptated, solid-cystic pelvic mass occupying the retrovesical space. No suspected areas were detected in the peripheral zone of the prostate. In-office cystoscopy was performed to rule out a bladder malignancy. No lesions were found within the bladder; however, unusual bleeding from the seminal colliculus was

${ }^{1}$ Department of Urology

${ }^{2}$ Department of Pathology

Careggi Hospital, University of Florence, Florence, Italy

Submitted: Jan 27, 2015; Revised: Feb 20, 2015; Accepted: Feb 27, 2015; Epub: Mar 5, 2015

Address for correspondence: Riccardo Campi, MD, Clinica Urologica I, Azienda Ospedaliera Careggi, Università di Firenze, Viale San Luca, 50134, Firenze, Italy E-mail contact: riccardo.campi@gmail.com found. The right ureteral orifice had also been pushed cranially, likely by extrinsic compression.

\section{Diagnostic Assessment and Magnetic Resonance Imaging Findings}

The patient underwent a urography-computed tomography scan, which confirmed the presence of a large mass with undefined boundaries and poor contrast enhancement occupying the retrovesical space. The relationships among the mass, rectum, and bladder were unclear. No abnormalities of the upper urinary tract and no pathologic pelvic lymph nodes were found. To further characterize the nature of the mass and to analyze its relationships with the adjacent organs, magnetic resonance imaging was performed. A retrovesical $6.0-\times 4.5-\mathrm{cm}$, well-defined, pseudonodular mass, arising from the right seminal vesicle (SV) and vas deferens (VD), was found cranial to the prostate (Figure 1). The signal was irregular and heterogeneous on $\mathrm{T}_{1}$-weighted images, likely owing to mixed serous-hemorrhagic remains. TRUS-guided prostate and SV biopsies were performed to exclude primary or secondary malignancies. No neoplastic proliferation was found in any of the samples from the prostate and SV mass.

\section{Management and Outcome}

The patient was scheduled for nerve-sparing (NS) robot-assisted laparoscopic vesiculectomy (RALV). A 4-arm transperitoneal 

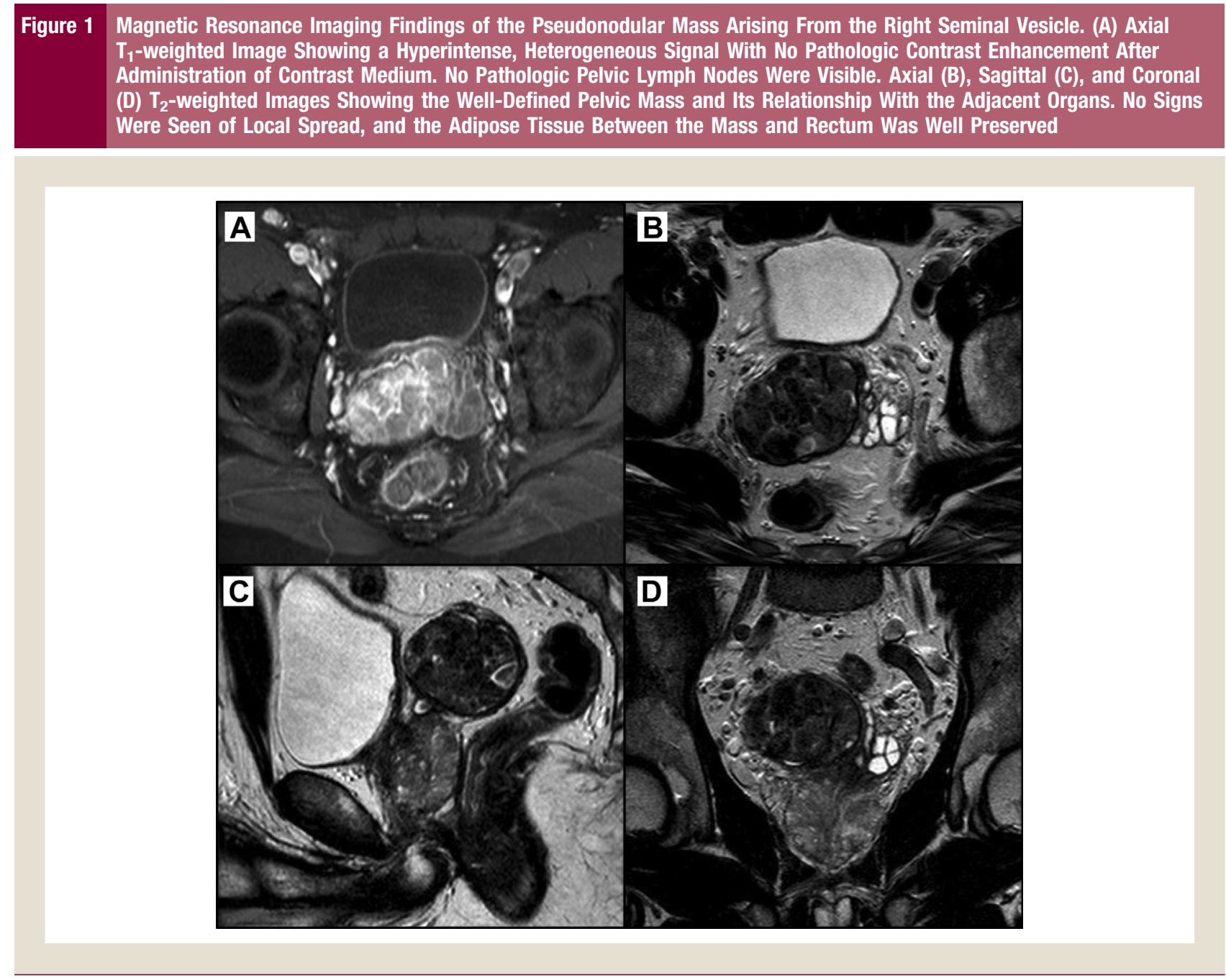

approach, using a $0^{\circ}$ lens, was adopted. After a transversal incision of the peritoneum at the level of the Douglas pouch, a voluminous mass, firmly adherent to the prostate, the left SV, and surrounding tissues, was found. The plane between the mass, rectum, and bladder was carefully and bluntly developed using monopolar scissors and, if needed, a bipolar Maryland dissector, until the tumor had been completely released from the surrounding adhesions. The left VD and SV were preserved during the dissection. The neurovascular bundles were approached bilaterally in an athermal, traction-free manner to preserve continence and potency. The specimen was then removed intact through the camera port using a retrieval bag. Accurate hemostatic control was achieved, and a tube drain was positioned. The console time and estimated blood loss was 120 minutes and $50 \mathrm{~mL}$, respectively. No intraoperative complications were recorded. The postoperative course was uneventful, and the patient was discharged on the fourth postoperative day with normal blood test results and spontaneous voiding. The 2-year follow-up examination showed no evidence of disease recurrence. At the last follow-up examination, the patient was free of symptoms with full preservation of continence and potency.

\section{Histopathologic Analysis}

The histopathologic examination showed a $7.0 \times 4.5 \times 4.5-\mathrm{cm}$ SV cystadenoma, according to the World Health Organization (WHO) classification criteria (Figure 2). ${ }^{1}$ The stroma resembled the usual fibromuscular stroma of SVs. No significant cytologic atypia, mitotic activity, or necrosis was present. The histochemical panel showed modest positivity for cytokeratin (CK) 7, and the PSA, prostatic acid phosphatase, and CK20 test results were negative. The proliferation index, determined using the immunohistochemical assay and $\mathrm{Ki} 67$, was $<1 \%$.

\section{Discussion}

Primary diseases of the SVs are very rare. Benign tumors can appear as complex, solid cystic retrovesical masses ${ }^{1}$ and are often totally asymptomatic. However, they can also lead to LUTS and unspecific signs, such as hematuria, hematospermia, perineal or postcoital discomfort, and painful defecation. ${ }^{2}$ Occasionally, infertility will be the main feature. The differential diagnosis can be challenging because other pathologic entities, such as SV cysts, diverticula of the ejaculatory ducts, acute inflammatory diseases, abscesses, amyloidosis, and malignancies (mostly arising from the 

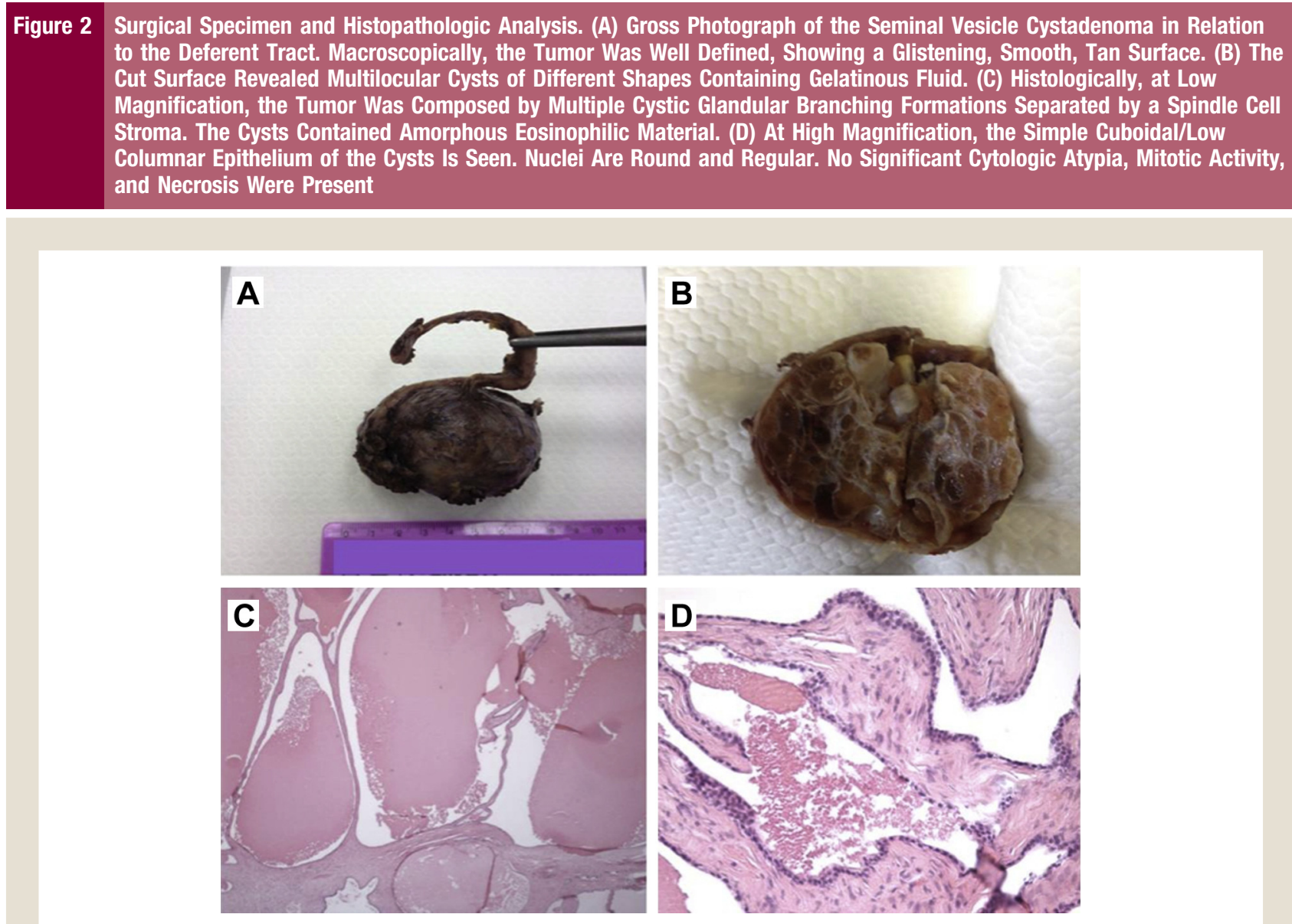

prostate, bladder, or rectum) can show the same imaging features. ${ }^{3}$ Therefore, the differential diagnosis must use a multimodality approach. The overall preoperative characterization of the tumor is critical to identify the most appropriate surgical strategy, with the first priority the exclusion of a primary or secondary malignancy.

We have presented a case of a large SV cystadenoma managed with NS RALV. A review of the English-language published studies of SV cystadenoma was performed using the Medline, Embase, and Web of Science databases to October 2014. Twenty case reports have been published on SV cystadenoma (Table 1). The median patient age and median tumor diameter was 49 years (interquartile range $[\mathrm{IQR}], 42-51$ years) and $7.0 \mathrm{~cm}$ (IQR, 5.0-12.0 cm), respectively. No perioperative complications were reported in the published series. Local recurrence developed in 2 patients $(10 \%)$ after 2 and 3 years, respectively. Nonetheless, the follow-up period was highly variable among the studies. The differential use of diagnostic investigations and surgical approaches for SV cystadenoma in the published series is shown in Figure 3. Analyzing the current published data, the most useful diagnostic investigations for the detection and characterization of SV cystadenoma were TRUS, MRI, and preoperative biopsy. The findings from cystoscopy and other techniques usually integrated the diagnosis. The diagnostic workup should always exclude congenital abnormalities of the upper urinary tract, especially renal agenesis. Owing to its multiplanar capability and excellent tissue contrast and resolution, endorectal MRI is the most accurate tool to accurately define the anatomic relationships of the tumor during surgical planning. ${ }^{3}$ When the imaging findings are unspecific or inconclusive, TRUS-guided focused biopsies are critical to obtain a precise histopathologic characterization of the lesion. Cystadenoma must be distinguished from mixed epithelial-stromal tumors (MEST) of SVs, which has been reported in previous studies with many different names. ${ }^{4}$ Currently, specific histological criteria must be fulfilled for the definition of MESTs, and the WHO classification has clearly separated this entity from cystadenoma. ${ }^{1,3}$ The differential diagnosis, based on the histologic analysis of the tumor stroma, is an important prognostic factor. Although MESTs usually show benign behavior, they can express histologic and clinical characteristics of malignancy ${ }^{4}$ and could potentially require more radical options. In contrast, seminal vesiculectomy is the recommended treatment of SV solid masses that are benign on biopsy, if symptomatic and with no evidence of local spread. ${ }^{2}$

Various surgical approaches have been described in published studies for SV cystadenoma. Owing to the anatomic location, surgical access to the SVs can be challenging, and the decision mainly relies on the expertise of the surgeon. ${ }^{2}$ Most cases in the published studies were managed with an open technique using an anterior transvesical ${ }^{5}$ or a retrovesical ${ }^{6}$ approach. Radical cystoprostatovesiculectomy has also been performed. ${ }^{7}$ After the first report of the use of a laparoscopic approach to SVs by 
Table 1 Strategies for Diagnosis and Surgical Approaches for Seminal Vesicle Cystadenoma According to Published Series

\begin{tabular}{|c|c|c|c|c|c|c|}
\hline Study & $\begin{array}{c}\text { Patient } \\
\text { Age (years) }\end{array}$ & \begin{tabular}{|c|} 
Tumor Size \\
(Greatest \\
Diameter) $(\mathrm{cm})$
\end{tabular} & $\begin{array}{l}\text { Diagnostic } \\
\text { Strategy }\end{array}$ & $\begin{array}{l}\text { Surgical } \\
\text { Procedure }\end{array}$ & $\begin{array}{l}\text { Perioperative } \\
\text { Complication }\end{array}$ & $\begin{array}{l}\text { Local Recurrence } \\
\text { After Surgery } \\
\text { (years) }\end{array}$ \\
\hline $\begin{array}{l}\text { Soule et al }{ }^{16}, \text { Proc Staff Meet } \\
\text { Mayo Clin, } 1951\end{array}$ & 47 & 14 & & Open (conservative) & No & No \\
\hline Damjanov et $\mathrm{al}^{17}$, J Urol, 1974 & 52 & 5.5 & Autopsy & & No & No \\
\hline $\begin{array}{l}\text { Lundhus et al }{ }^{18} \text {, Scand J Urol } \\
\text { Nephrol, } 1984\end{array}$ & 39 & 7.4 & & Open (CysProV) & No & No \\
\hline $\begin{array}{l}\text { Mazur et } \mathrm{al}^{19} \text {, Am J Surg Pathol, } \\
1987\end{array}$ & 49 & 7 & & Open (conservative) & No & Yes (2) \\
\hline Bullock et a ${ }^{20}, J$ R Soc Med, 1988 & 59 & 12 & & LV & No & Yes (3) \\
\hline \multicolumn{7}{|l|}{$\begin{array}{l}\text { Raghuveer et al }{ }^{21} \text {, Indian J Pathol } \\
\text { Microbiol, } 1989\end{array}$} \\
\hline Mazzucchelli et al ${ }^{22}$, J Urol, 1992 & 63 & 3 & & Open (conservative) & No & No \\
\hline $\begin{array}{l}\text { Ranschaert et a }\left.\right|^{23} \text {, J Belge Radiol, } \\
1992\end{array}$ & 50 & 12 & & Open (conservative) & No & No \\
\hline $\begin{array}{l}\text { Lagalla et al }{ }^{24} \text {, Abdom Imaging, } \\
1993\end{array}$ & 33 & & $\begin{array}{l}\text { TRUS, CT, FNA, } \\
\text { cytology, biopsy }\end{array}$ & Open (conservative) & No & No \\
\hline Santos et al ${ }^{25}$, Pathology, 2001 & 49 & 15 & & Open (conservative) & No & No \\
\hline Gil et $\mathrm{al}^{26}$, Int Braz J Urol, 2003 & 49 & 7 & Abd US, CT, MRI & $\begin{array}{c}\text { Open (conservative, } \\
\text { retrovesical approach) }\end{array}$ & No & No \\
\hline Lee et $\mathrm{al}^{6}{ }^{6}$ Int J Urol, 2006 & 46 & 7.5 & $\begin{array}{l}\text { CT, MRI, explorative } \\
\text { laparotomy }\end{array}$ & Open (conservative) & No & No \\
\hline Lorber et al, ${ }^{5}$ Eur Urol, 2011 & 52 & 14 & $\begin{array}{l}\text { CT, MRI, Abd US, } \\
\text { biopsy }\end{array}$ & $\begin{array}{l}\text { Open (conservative, } \\
\text { transvesical) }\end{array}$ & No & No \\
\hline Kural et al, ${ }^{14} \mathrm{~J}$ Endourol, 2011 & 48 & 6 & TRUS, biopsy & RALV & No & No \\
\hline $\begin{array}{l}\text { Ploumidis et al, }{ }_{1}^{15} \text { Int J Surg } \\
\text { Case Rep, } 2012\end{array}$ & 45 & 17.2 & $\begin{array}{l}\text { TRUS, CT, MRI, CYS, } \\
\text { FNA-cytology, } \\
\text { intraoperative biopsy }\end{array}$ & RALV & No & No \\
\hline Arora et $\mathrm{al}^{27}$, Urology, 2013 & 23 & & TRUS, MRI & Open (conservative) & No & No \\
\hline Zhu et al, ${ }^{11}$ Asian J Androl, 2013 & 31 & 5 & CT, MRI & LV & No & No \\
\hline Zhang et al, ${ }^{13}$ Urology, 2013 & 32 & 5 & & LV & No & No \\
\hline Zhang et $\mathrm{al},{ }^{13}$ Urology, 2013 & 64 & 4.5 & & LV & No & No \\
\hline Zhang et $\mathrm{al},{ }^{13}$ Urology, 2013 & 50 & 3.8 & & LV & No & No \\
\hline
\end{tabular}

Abbreviations: Abd US = abdominal ultrasonography; CT = computed tomography; CYS = cystoscopy; CysProV = cystoprostatovesiculectomy; FNA = fine needle aspiration; LV = laparoscopic vesiculectomy; $\mathrm{MRI}=$ magnetic resonance imaging; TRUS = transrectal ultrasonography.

Kavoussi et $\mathrm{al}^{8}$ in 1993 , minimally invasive surgery (MIS) has been increasingly performed to approach retrovesical structures such as tumors or cysts. ' Transperitoneal laparoscopic vesiculectomy for SV cystadenoma was recently performed, achieving optimal oncologic outcomes and easy recovery after surgery. ${ }^{10,11}$ With the advantages over conventional laparoscopy, in particular, the magnified 3-dimensional vision, EndoWrist instrument technology, and superior ergonomic environment for the operating surgeon, a robotic approach has been increasingly selected for the treatment of cysts and other abnormalities of the SVs. ${ }^{12,13}$ To date, only 2 cases of SV cystadenoma have been managed with RALV using a transperitoneal approach. ${ }^{14,15}$ This technique replicates the surgical principles of posterior approach to $\mathrm{SV}$ s during robot-assisted radical prostatectomy (RARP). In this context, some investigators have recommended previous experience in RARP before approaching a retrovesical mass with the robotic technique. ${ }^{15}$

In the present case, the diagnostic workup could safely exclude primary or secondary malignancies of the SVs, avoiding any need for intraoperative biopsies. NS RALV provided easy access to the retrovesical anatomic structures, with optimal exposure of the SV mass and guaranteed optimal functional and oncologic outcomes. Although most reported cases of SV cystadenoma were managed with open surgery, MIS can be considered the new reference standard for the treatment of such benign tumors. Additional studies are needed to confirm the feasibility and oncologic safety of this technique.

\section{Conclusion}

We have presented a case of a large SV cystadenoma causing LUTS and gross hematuria managed by NS RALV. Primary tumors of SVs are very rare. The differential diagnosis can be challenging and must use a multimodality approach. Once the benign nature of the tumor has been confirmed at preoperative biopsy, minimally invasive seminal vesiculectomy can achieve optimal perioperative and oncologic outcomes and can be safely considered the standard reference treatment.

\section{Disclosure}

The authors have stated that they have no conflicts of interest. 
Overview of the Differential Use of Diagnostic Investigations and Surgical Treatment Options for Seminal Vesicle

Cystadenoma Among Published Series. (A) In 10 of 20 Studies (50\%), the Diagnostic Workup Was Accurately Described. Ultrasonography (US) Was Used in 6 Cases (60\%), Endorectal Magnetic Resonance Imaging (MRI) in 7 (70\%), Computed Tomography (CT) in 6 (60\%), Preoperative Biopsy in $4(40 \%)$, Intraoperative Biopsy and Explorative Laparotomy in 1 Case (10\%) Each, Cystoscopy, Fine Needle Aspiration, Cytology, and Other Modalities in $2(20 \%)$. Finally, 1 Case (10\%) Was Found at Autopsy. (B) In 19 of 20 Studies (95\%), the Surgical Technique Was Well Defined. An Open Approach Was Used in Most Cases, With Tumorectomy (Tum) in 11 Cases (58\%) and Radical Cystoprostatovesiculectomy (CysProV) in 1 (5\%). Laparoscopic Vesiculectomy (LV) and Robot-Assisted LV (RALV) Was Performed in $5(26 \%)$ and 2 (11\%) Cases, Respectively

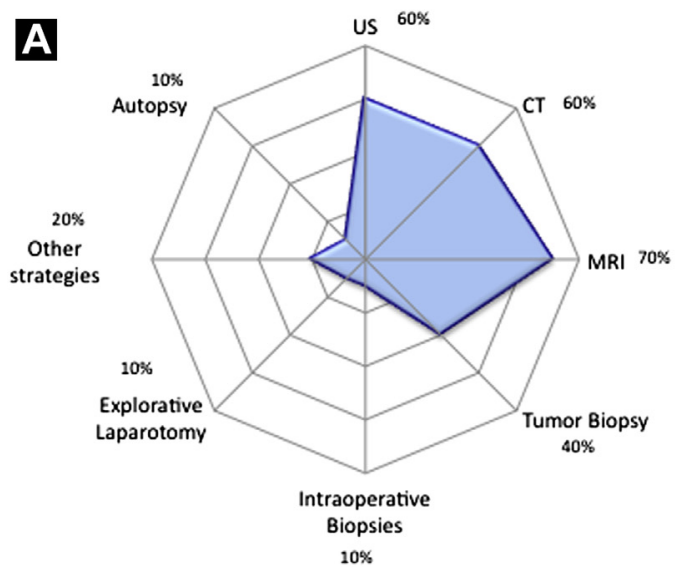

$\mathbf{B}$

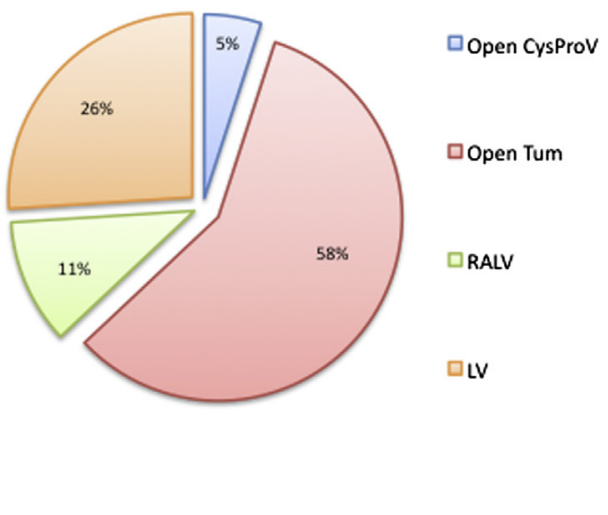

\section{References}

1. Iczkowski KA, Samaratunga HM, Cheng L, et al. Tumors of the semina vesicles. In: Eble JN, Sauter G, Epstein JI, Sesterhenn IA, eds. World Health Organization Classification of Tumours: Pathology and Genetics of Tumours of the Urinary System and Male Genital Organs. Lyon, France: IARC Press; 2004: 214-5.

2. Kavoussi PK, Costabile RA. Surgery of the scrotum and seminal vesicles. In: Wein AJ, Kavoussi LR, Novick Partin AW, Peters CA, eds. Campbell-Walsh Urology. Philadelphia, PA: Elsevier Health Sciences; 2012:1012-22.

3. Kim B, Kawashima A, Ryu F-A, et al. Imaging of the seminal vesicle and vas deferens. Radiographics 2009; 29:1105-21.

4. Monica B, Larosa M, Facchini F, et al. Low grade epithelial stromal tumour of the seminal vesicle. World J Surg Oncol 2008; 6:101.

5. Lorber G, Pizov G, Gofrit ON, Pode D. Seminal vesicle cystadenoma: a rare clinical perspective. Eur Urol 2011; 60:388-91.

6. Lee CB, Choi H-J, Cho DH, Ha U-S. Cystadenoma of the seminal vesicle. Int J Urol 2006; 13:1138-40.

7. Baschinsky DY, Niemann TH, Maximo CB, Bahnson RR. Seminal vesicle cystadenoma: a case report and literature review. Urology 1998; 51:840-5.

8. Kavoussi LR, Schuessler WW, Vancaillie TG, Clayman RV. Laparoscopic approach to the seminal vesicles. J Urol 1993; 150:417-9.

9. Passerotti C, Cendron M, Gargollo P, et al. Minimally invasive surgical approaches to retrovesical structures. Int J Med Robot 2007; 3:307-11.

10. Zhang D-X, Li Y, Li X-J, et al. Transperitoneal laparoscopic excision of primary seminal vesicle benign tumors: surgical techniques and follow-up outcomes. Urology 2013; 82:237-41, 2013.

11. Zhu J-G, Chen W-H, Xu S-X, et al. Cystadenoma in a seminal vesicle is cured by laparoscopic ablation. Asian J Androl 2013; 15:697-8.

12. Hong YK, Onal B, Diamond DA, et al. Robot-assisted laparoscopic excision of symptomatic retrovesical cysts in boys and young adults. J Urol 2011; 186:2372-8.
13. Allaparthi S, Blute RD Jr. Novel application of da Vinci robotic system in patients of Zinners syndrome - case report and review of literature. Can J Urol 2010; 17:5109-13.

14. Kural AL, Tufek I, Keskin MS, et al. Robot assisted excision of cystadenoma of the seminal vesicle. J Endourol 2011; 25(suppl 1):A344.

15. Ploumidis A, Sooriakumaran P, Philippou P, Wiklund NP. Robotic-assisted laparoscopic vesiculectomy for lower urinary tract obstruction by a large seminal vesicle cyst. Int I Surg Case Rep 2012; 3:375-8.

16. Soule EH, Dockerty MB. Cystadenoma of the seminal vesicle, a pathologic curiosity. Report of a case and review of the literature concerning benign tumors of the seminal vesicle. Proc Staff Meet Mayo Clin 1951; 26:406-14.

17. Damjanov I, Apic R. Cystadenoma of seminal vesicles. J Urol 1974; 111:808-9.

18. Lundhus E, Bundgaard N, Sørensen FB. Cystadenoma of the seminal vesicle. A case report. Scand I Urol Nephrol 1984; 18:341-2.

19. Mazur MT, Myers JL, Maddox WA. Cystic epithelial-stromal tumor of the seminal vesicle. Am J Surg Pathol 1987; 11:210-7.

20. Bullock KN. Cystadenoma of the seminal vesicle. J R Soc Med 1988; 81:294-5.

21. Raghuveer CV, Nagarajan S, Aurora AL. Papillary cystadenoma of seminal vesicle. A case report. Indian J Pathol Microbiol 1989; 32:314-5.

22. Mazzucchelli L, Studer UE, Zimmermann A. Cystadenoma of the seminal vesicle: case report and literature review. I Urol 1992; 147:1621-4.

23. Ranschaert ER, Van Mulders P, Usewils R, et al. An unusual low-abdominal tumor: cystadenoma of the seminal vesicle. J Belge Radiol 1992; 75:105-9.

24. Lagalla R, Zappasodi F, Lo Casto A, Zenico T. Cystadenoma of the seminal vesicle: US and CT findings. Abdom Imaging 1993; 18:298-300.

25. Santos LD, Wong CS, Killingsworth M. Cystadenoma of the seminal vesicle: report of a case with ultrastructural findings. Pathology 2001; 33:399-402.

26. Gil AO, Yamakami LY, Genzini T. Cystadenoma of the seminal vesicle. Int Braz J Urol 2003; 29:434-6.

27. Arora A, Sharma S, Seth A. Unusual retrovesical cystic mass in a male patient. Urology 2013; 81:e23-4. http://dx.doi.org/10.1016/j.urology.2012.10.022. 